\title{
Integrating multiple dimensions of biodiversity to inform global parrot conservation
}

\section{Authors:}

Kevin R. Burgio ${ }^{1,2 *}$, Katie E. Davis ${ }^{3}$, Lindsay M. Dreiss ${ }^{4}$, Laura M. Cisneros ${ }^{5,6}$, Brian T. Klingbeil $^{1,7}$, Steven J. Presley ${ }^{1,6,7}$, Michael R. Willig ${ }^{1,6,7}$

\section{Affiliations:}

${ }^{1}$ Department of Ecology and Evolutionary Biology, University of Connecticut; 75 N. Eagleville Rd. U-3043, Storrs, CT, 06269.

${ }^{2}$ Education Department, Cary Institute for Ecosystem Studies, Millbrook, NY, 12545.

${ }^{3}$ Department of Biology, University of York, Wentworth Way, York, YO10 5DD, UK.

${ }^{4}$ Center for Conservation Innovation, Defenders of Wildlife, $113017^{\text {th }}$ Street NW, Washington, DC 20036.

${ }^{5}$ Department of Natural Resources and the Environment, University of Connecticut, 1376 Storrs Road, Storrs, Connecticut 06269.

${ }^{6}$ Institute of the Environment, University of Connecticut, 3107 Horsebarn Hill Road, Storrs, CT, 06269.

${ }^{7}$ Environmental Sciences and Engineering, University of Connecticut, 3107 Horsebarn Hill Road, Storrs, CT, 06269.

\section{*Corresponding Author / Lead Contact:}

Kevin R. Burgio - kevin.burgio@uconn.edu - (860) 230-7856 


\section{ABSTRACT}

Because biodiversity is increasingly threatened by habitat destruction and climate change, conservation agencies face challenges associated with an uncertain future. In addition to changes associated with climate and land use, parrots are threatened by hunting and capture for the pet trade, making them the most at-risk order of birds in the world. Parrots provide key ecosystem services, but remain understudied compared to other major bird orders despite their high extinction risk and ecological importance. Species richness is often used to identify high priority areas for conserving biodiversity. By definition, richness considers all species to be equally different. However, ongoing research emphasizes the importance of incorporating ecological functions (functional diversity) or evolutionary relationships (phylogenetic diversity) to more fully understand patterns of biodiversity, suggesting that using functional and phylogenetic information could improve conservation strategies. These distinctions among dimensions of biodiversity are important, because (1) areas of high species richness do not always represent areas of high functional or phylogenetic diversity, and (2) functional or phylogenetic diversity may better predict ecosystem function and evolutionary potential, which are essential for effective long-term conservation policy and management.

Our objective was to create a framework for identifying areas of high species richness, functional diversity, and phylogenetic diversity within the global distribution of parrots We combined species richness, functional diversity, and phylogenetic diversity into an Integrated Biodiversity Index (IBI) to identify global biodiversity hotspots for parrots. We found important spatial mismatches among dimensions, which demonstrate that species richness is not always an effective proxy for other dimensions of parrot biodiversity. The IBI is an integrative and flexible index that can incorporate multiple dimensions of biodiversity, resulting in an intuitive and more 
24 direct way of assessing comprehensive goals in conservation planning (i.e., healthy ecosystem

25 functioning and climate change resilience).

26 KEYWORDS

$27 \mathrm{c}$

28

INTRODUCTION

As we enter the early stages of the "Sixth Mass Extinction" (Ceballos et al. 2015), conservation agencies are struggling to face the challenges of a less certain future (Armsworth et al. 2015) as a consequence of habitat conversion and climate change (Urban et al. 2015). While most taxa are at risk, parrots (Psittaciformes) are especially so, as they are the most threatened order of birds, with $\sim 43 \%$ of species listed as near-threatened or worse, and with $\sim 28 \%$ listed as threatened or worse by the IUCN (IUCN 2015, Olah et al. 2016). Furthermore, 56\% of parrot populations are currently thought to be in decline (IUCN 2015). However, estimates of bird density exist for only $25 \%$ of species, and those estimates suggest that parrot density is higher inside of protected areas than outside of them (Marsden \& Royle 2014), demonstrating the critical importance of conservation action.

Parrots provide many important ecosystem functions, including invertebrate pest management, pollination, seed dispersal, and genetic-linking of plant communities, making them

42 "keystone mutualists" (Tella et al. 2015, Blanco et al. 2015, Blanco et al. 2016). Parrots also

43 forage on plants that are toxic and poisonous to many vertebrate species (Gilardi \& Toft 2012,

44 Blanco et al. 2015), allowing them to find food and persist in habitats where other frugivorous

45 species cannot (Gilardi \& Toft 2012). Given the critical ecosystem services parrots provide, their

46 loss may have detrimental effects on the persistence of many plant species, thereby contributing 
47 to ecosystem instability. Conversely, some parrot species have been spreading into new areas,

48 primarily as a consequence of the pet trade, which has led to human/wildlife conflicts in Europe

49 (White et al. 2019) and the introduction of 25 non-native species that now breed in the USA

50 (Uehling et al. 2019).

In general, parrots have long generation times, low population densities, and high risk of

52 being hunted or trapped (Pires 2012, Marsden \& Royle 2014), all characteristics associated with

53 high extinction risk (Bennett and Owens 1997, Cardillo et al. 2005). Predictably, parrot species

54 that are larger-bodied and have longer generation times are generally found at relatively lower

55 densities (Marsden \& Royle 2014) and are more likely than are smaller parrot species to be

56 obligate tree-cavity nesters (Renton et al. 2015), increasing extinction risk (Jones et al. 2006,

57 Olah et al. 2016). Despite being the most-threatened order of birds, parrots are relatively

58 understudied compared to other orders of birds (Brito \& Orpea 2009, Ducatez \& Lefebvre 2014).

59 The lack of research may explain why density estimates, one of the most important factors in

60 determining conservation status (Mace et al. 2008), are inadequate for most parrot species

61 (Marsden \& Royle 2014).

In addition to the effects of climate change and habitat loss resulting from agriculture or

63 logging, other anthropogenic activities such as hunting and trapping are among the biggest

64 threats to parrots (Snyder et al. 2000, Olah et al. 2016). Logging and agricultural conversion of

65 habitats disproportionately affect parrots because a majority of parrot species $(\sim 70 \%)$ are forestdependent (Olah et al. 2016). Most parrot species ( 78\%) also rely on tree-cavities for nesting

67 (Renton et al. 2015), and nesting in some species is limited to a few tree species (Renton and 68 Brightsmith 2009). 
Over the past few decades, one of the most common methods for identifying areas of

70 highest conservation priority has been based on the "hotspot concept" (Reid 1997, Myers et al.

71 2000), which uses existing species range maps to prioritize conservation efforts where species

72 richness or richness of endemic species is highest. More recently, the multidimensional nature of

73 biodiversity has emerged as a critical consideration for conservation (e.g., Isaac et al. 2007,

74 Mazel et al. 2014, Brum et al. 2017, Pollock et al. 2017) and considerations of irreplaceability

75 and complementarity have supplemented the hotspot concept via spatial prioritization approaches

76 (e.g. Andelman and Willig 2002, 2003; Zonation and Marxan; reviewed in Moilanen et al. 2009).

77 Regions of high functional diversity (a measure of ecological trait diversity within an

78

79

80

81

82 assemblage) or phylogenetic diversity (a measure of evolutionary diversity within an assemblage) may not coincide with areas with high species richness (e.g. for mammals; see Safi et al. 2011, Mazel et al. 2014, Brum et al. 2017). Consequently, calls to incorporate phylogenetic or functional biodiversity into conservation planning have arisen over the last couple of decades (Mace et al. 2003, Diaz et al. 2007).

Limited availability of data at appropriate scales, and the complex nature of metrics used to quantify functional or phylogenetic diversity, have inhibited until very recently the incorporation of this information into conservation planning approaches that prioritize land for protection (e.g. Brum et al. 2017, Pollock et al. 2017). Phylogenetic or functional diversity may be better indicators of community resilience than is species richness (Naeem et al. 2012).

Conserving functional diversity is critical for maintaining ecosystem functions (Naeem et al. 2012), and thus for maintaining critical ecosystem services, making it an important consideration in conservation (Chan et al. 2006, Diaz et al. 2007, Cimon-Morin et al. 2013, Kosman et al. 2019). Nonetheless, cases that incorporate functional diversity in conservation research are rare 
92 (but see Devictor et al. 2010 and Mazel et al. 2014). Maintaining the capacity for future

93 adaptation is an important consideration for communities undergoing rapid climatic and

94 environmental changes, suggesting that phylogenetic diversity should be given consideration

95 when determining conservation goals (Naeem and Li 1997, Cardinale et al. 2012). Moreover, the

96 loss of phylogenetic or functional diversity may be a better indicator than is the loss of species

97 richness in quantifying ecosystem vulnerability (Srivastava et al. 2012).

99 diversity, and phylogenetic diversity within the global distribution of parrots. We separately

100 calculated species richness, functional diversity, and phylogenetic diversity, and then combined

101 them into an Integrated Biodiversity Index (IBI) to identify global biodiversity hotspots to aid in

102 parrot conservation. Important spatial mismatches between dimensions indicate situations in

103 which species richness is not an effective proxy for other dimensions of parrot biodiversity.

104 METHODS

105 Data collection

106

107

108

109

110

\section{Distribution data}

We used range maps for all 398 extant species of parrot (Birdlife International 2015) following the taxonomy of del Hoyo et al. (2014) to inform spatially-explicit estimates of biodiversity at a global scale.

\section{Trait and phylogenetic data}

We estimated functional diversity using two types of data: categorical (binary) and mensural traits (Table 1). For each data type, we used a suite of traits that reflect particular niche axes and define functional components. Categorical traits included components of diet, foraging 
114 strategy, and foraging location, whereas mensural traits comprise body size and range size. For

115 each categorical trait, a species received a " 1 " if it exhibited the characteristic and a " 0 " if it did

116 not. For each body size, we used the average value for each species based on measurements of

117 multiple adults, when available. We obtained trait data for all parrot species from the literature

118 (see Burgio et al. [2019] for more details) and range size data from Birdlife International (2015).

119 We calculated phylogenetic diversity for each community using branch lengths found in a

120 recently-published time-calibrated phylogenetic supertree for all 398 extant parrots (Burgio et al.

121 2019).

122 Analyses

123 Biodiversity indices

124 We created a grid in ArcMap v.10.3 (ESRI, Redlands, CA, USA), using the Cylindrical

125 Equal Area projection, with each grid cell measuring 50 x $50 \mathrm{~km}$ (hereafter "grid cell"). For each

126 grid cell $(n=21,078)$, we estimated species richness as the number of species with a range

127 overlapping the cell. We estimated phylogenetic and functional diversity for each cell using

128 Rao's quadratic entropy (Rao’s Q; Botta-Dukát 2005). Rao’s Q measures the average difference

129 between all pairs of species, thereby reflecting multivariate dispersion. We obtained the average

130 phylogenetic or functional distances among species from pairwise dissimilarity matrices for the

131 phylogenetic and functional components, as well as separately for each of the six functional

132 categories. For the phylogenetic supertree, we populated a pairwise dissimilarity matrix via the

133 "cophenetic" function of the R package "ape" (v.3.5, Paradis et al. 2004). We used the Gower

134 metric from the R package "cluster" (v.2.0.4, Maechler et al. 2012) to calculate pairwise

135 functional dissimilarity matrices. 
To allow meaningful comparisons among dimensions, we transformed each metric into

137 its effective number of species or Hill number (hereafter numbers equivalent). The numbers

138 equivalent is the number of maximally dissimilar species that is required to produce an empirical

139 value of a diversity metric (Jost 2006). This transformation facilitates intuitive interpretation of

140 differences among assemblages and dimensions because indices are expressed in the same units

141 (Jost 2006, Chao et al. 2014). Species richness is its own numbers equivalent. We transformed

142 Rao's Q values into numbers equivalents using R functions developed by de Bello et al. (2010).

\section{Integrated Biodiversity Index}

The Integrated Biodiversity Index (IBI) combines numbers equivalent transformations of

146 Rao's Q for phylogenetic and functional diversity (all traits combined) with species richness. We

147 scaled each dimension of biodiversity to a range from 0 to 1 so that each would have equal

148 opportunity to contribute to the IBI value. Without such scaling, species richness would likely

149 dominate spatial patterns of biodiversity. The IBI is the sum of the scaled representations of

150 species richness (S), functional diversity (FD), and phylogenetic diversity (PD) for a particular

151 grid cell $(i)$ :

$$
I B I=\sum_{i}\left[\frac{\left(S_{i}-S_{\min }\right)}{\left(S_{\max }-S_{\min }\right)}+\frac{\left(F D_{i}-F D_{\min }\right)}{\left(F D_{\max }-F D_{\min }\right)}+\frac{\left(P D_{i}-P D_{\min }\right)}{\left(P D_{\max }-P D_{\min }\right)}\right] .
$$

152 As a consequence of the numbers equivalent transformation and scaling functions, IBI values

153 range from 0 to 3 and equally weight each dimension of diversity (i.e. a value of " 0 " would mean

154 low combined biodiversity while a value of " 3 " would be highest in combined biodiversity).

\section{RESULTS}


Species richness of parrots is highest in the Amazon Basin of South America, along the

158 southeastern coast of Australia, and in the mountainous region of New Guinea (Fig. 1a).

159 Functional diversity is highest in the dry Chaco of South America (Fig. 1b). Our measure of

160 functional diversity represents multivariate dispersion, which is greatest for assemblages that

161 represent many functional types, but that have low redundancy in those functions. Dry Chaco

162 parrot assemblages have low species richness (Fig. 1a) and species that differ greatly from each

163 other in functional traits associated with diet and foraging location. Phylogenetic diversity is

164 highest in Australia, arising primarily from the diversification of multiple subfamilies within the

165 Psittacidae, and the fact that cockatoos (Cacatuidae), which represent a deep split in the parrot

166 phylogeny (Fig. 2), are endemic to Australia and Oceania.

IBI is highest in Australia and New Guinea (Fig. 3), and moderate in northern and central

168 South America. For example, in South America, species richness is highest in the Amazon Basin

169 (Fig. 4a), phylogenetic diversity is fairly evenly distributed throughout the continent (Fig. 4b),

170 and functional diversity is highest in the dry Chaco (Fig. 4c). Although IBI equally weights each

171 of the three dimensions (Fig. 4d), considerable spatial mismatches exist between hot spots of

172 species richness and IBI (Figs. 4e, S1).

\section{DISCUSSION}

In general, most of Australia, the island of New Guinea, and to a lesser extent, the

176 Amazon Basin, evince the highest values of IBI. Because parrots and regions with the highest

177 levels of species richness are generally understudied (Brito \& Orpea 2009, Ducatez \& Lefebvre

178 2014, Wilson et al. 2016), the results of IBI analysis helps to focus future research on parrots in

179 areas of greatest need. 
Aside from multiple dimensions of biodiversity, considerations of spatial scale are

181

182

183

184

185

186

187

188

189

190

191

192

194

195

196

197

198

199

200

201

202

necessary for effective conservation planning. For example, most conservation agencies are

regional or local in scale, and cannot engage in global conservation planning. For instance, the

Neotropics score rather low (Fig. 2) in phylogenetic diversity compared to other regions because only one subfamily (Arinae) is endemic there. However, functional diversity is highest in the Chaco region of South America, likely because it is a harsh environment with low productivity;

it likely cannot support multiple populations that perform similar functions. The Arinae subfamily diversified relatively quickly (Davies et al. 2007, Wright et al. 2008) and is the most species-rich subfamily in the parrot phylogeny, accounting for the discrepancies between dimensions of biodiversity in South America (Fig. 4). Maps of functional and phylogenetic diversity generated using only species of parrots found in the Neotropics (i.e. the Arinae) likely would identify different areas of continental conservation concern than those presented here (Figs. 2 \& 4).

The areas we identified as high priorities generally correspond with results from other global prioritization research, but with a few notable exceptions. For instance, Myers et al. (2000), who initiated the "hotspots" concept, and included a wide variety of taxa, also identified Brazil's Cerrado and the southern expanse of the tropical Andes as areas of high priority; but did not prioritize central Australia. Recent research has incorporated spatial prioritization and multiple dimensions of diversity. For instance, high priority areas for birds (Pollock et al. 2017) and mammals (Brum et al. 2017) are the Andes, equatorial Africa, Indonesia, and New Guinea, which coincide well the patterns of high IBI for parrots, though our results also emphasize southeastern Australia and the Amazon Basin, likely due to the unique diversification pattern of parrots. 
The incorporation of socioeconomic data into conservation decisions can help anticipate

204

205

206

207

208

209

210

211

212

213

214

215

216

217

218

219

220

221

222

223

224

new risks and adapt management targets accordingly (Armsworth et al. 2015). For example, high

levels of urbanization correlate with an increased number of threatened parrot species, and a

country's GDP (per capita) increases the threat level (Olah et al. 2016, Butchart et al. 2015).

Such an approach could identify areas within countries with increasing urbanization and

increasing per capita GDP, with relatively high levels of diversity, to allow early intervention,

before the effects of processes that lead to extinction (e.g. habitat loss and increased hunting) are irreversible.

If a conservation agency were to decide that hotspots of species richness were sufficient to set priorities for parrot conservation in South America, they would focus on the Amazon Basin (Fig. 4a), largely ignoring the high degree of functional diversity in the dry Chaco, which has the highest functional diversity of parrots in the world (Fig. 4c). However, by incorporating multiple aspects of biodiversity in the IBI, these aspects of biodiversity are weighted equally (Fig. 4d), allowing conservation agencies to make more informed decisions. Importantly, any particular dimension of biodiversity can be emphasized (or de-emphasized) within the IBI framework depending on the goals of a particular project. The mismatch between species richness and IBI (Figs 4e, S1) illustrates the importance of all aspects of biodiversity, and the problems with assumptions that protecting one dimension means that other dimensions are protected effectively. Spatial mismatches among hotspots of different dimensions have also been documented for mammals (Mazel et al. 2014). Conservation planners and practitioners should consider the scale and goals of conservation plans and should incorporate relevant information into an integrated framework to understand the relative value of particular policy options before taking action. 
Although we do not explore extinction risk specifically, parrot species with larger ranges generally are at less risk of extinction, whereas parrot species with larger bodies or that are more dependent on forest may be at increased risk for extinction (Jones et al. 2006, Olah et al. 2016).

228 Because these, and other traits, may be good indicators of extinction risk for parrots, it may be useful to consider each functional component separately. Mapping the areas of relatively low diversity in traits such as body size (Fig. S2), location (Fig. S4), or range size (Fig. S6), may be a good first step in identifying assemblages that may be at greater risk for extinction. Critically, simultaneous consideration of all components of functional diversity can obscure important patterns that are relevant to particular conservation issues (Spasojevic \& Suding 2012, Lopez et ecosystem services may wish to focus on diet and foraging strategy diversity (Figs S3 and S5, respectively), as opposed to functional diversity.

The network of conservation areas in France provides different levels of protection for 238 bird species richness, phylogenetic diversity, and functional diversity (Devictor et al. 2010). A 239 potential extension of our framework could evaluate how well particular dimensions of 240 biodiversity are protected, as a means of weighting the IBI equation to emphasize or de241 emphasize particular dimensions when prioritizing areas to protect. Similarly, measures such as

242 "ED” (Evolutionary Distinctiveness; Isaac et al. 2007), "EDGE” (Evolutionary Distinctiveness / 243 Globally Endangered; Isaac et al. 2007), and "EDR" (Evolutionary Distinctiveness Rarity; Jetz et 244 al. 2014) can be added or can replace phylogenetic diversity to ensure that distinct clades of the 245 parrot tree are given more weight when assessing conservation priorities. Climate change will have direct and indirect effects on species range shifts (Jones et al. 247 2016). Direct effects are based on the physiological tolerances of species, which will track their 
248 climatic niches as spatial patterns of temperature and precipitation change. Indirectly, climate

249 change will affect land-use patterns by humans (Turner et al. 2010), which may limit or form

250 barriers against the dispersal of individuals (Faleiro et al. 2013). Preserving connectivity among

251 habitat patches may be a key element of effective conservation strategies in the face of climate

252 change (Schmitz et al. 2015), further supported here by the areas we identify as high diversity,

253 including the belt across central South America (Fig. 4). The effects of recent climate change

254 have been greater at high elevations and in tundra compared to tropical and subtropical lowlands

255 (Seddon et al. 2016) that harbor most species of parrots. Nonetheless, many parrot species occur

256 in areas that are sensitive to climate change. Based on a combination of species richness and the

257 number of threatened species and endemic species, Indonesia, Brazil, Australia, Colombia, and

258 Bolivia are the five highest priority countries for parrot conservation action (Olah et al. 2016).

Given the predicted extent and severity of effects of climate change, conservation

agencies face a daunting task. Conservation planning must balance current protection needs with

261 future expectations as species may become locally extinct, shift their ranges, or adapt to

262 changing conditions, possibly leading to the production of novel assemblages. Additional

263 complications for future conservation efforts include the push and pull between different scales

264 of conservation prioritization (i.e. the "actors" versus the "stage"; Tingley et al. 2014). Although

265 some conservation agencies may opt to focus on particular species due to public and political

266 values (Mace 2004), IBI is an integrative and flexible index that can incorporate multiple

267 dimensions of biodiversity, resulting in the intuitive way to assess more than just species

268 richness in conservation planning. 
We thank R. K. Colwell, C. Rittenhouse, M. Rubega, B. Walker, and an anonymous reviewer for providing valuable feedback. KRB was supported by National Science Foundation (NSF) grant \#DGE-0753455. Many of the methods in this paper were developed in part by participation of KRB, LMD, LMC, BTK, SJP, and MRW in an NSF-funded project entitled "The Dimensions of Biodiversity Distributed Graduate Seminar" awarded to S. Andelman and J. Parrish (DEB1050680). SJP and MRW were supported by the Center for Environmental Sciences \& Engineering at the University of Connecticut, as well as by an NSF award (DEB-1546686 and DEB-1831952).

\section{REFERENCES}

Andelman, S. J. and Willig, M. R. 2002. Alternative configurations of conservation reserves for Paraguayan bats: considerations of spatial scale. Cons Biol 16: 1352-1363.

Andelman, S. J. and Willig, M. R. 2003. Present patterns and future prospects for biodiversity in the Western Hemisphere. Ecol Letters 6:818-824.

Armsworth, P. R., Larson, E. R., Jackson, S. T., Sax, D. F., Simonin, P., Blossey, B., Green, N., Klein, M. L., Lester, L., Ricketts, T. H., Runge, M. C. and Shaw, M. R. 2015. Are conservation organizations configured for effective adaptation to global change? - Front Ecol Environ 13: 163-169.

Bennett, P. M. and Owens, I. P. 1997. Variation in extinction risk among birds: chance or evolutionary predisposition? - Philos Trans R Soc B Biol 264: 401-408.

BirdLife International. 2015. IUCN Red List for birds. Retrieved from http://www.birdlife.org

Blanco, G., Hiraldo, F., Rojas, A., Dénes, F. V. and Tella, J. L. 2015. Parrots as key multilinkers in ecosystem structure and functioning. - Ecol Evol 5: 4141-4160.

Blanco, G., Bravo, C., Pacifico, E. C., Chamorro, D., Speziale, K. L., Lambertucci, S. A., Hiraldo, F. and Tella, J. L. 2016. Internal seed dispersal by parrots: an overview of a neglected mutualism. - PeerJ 4: e1688.

Botta-Dukát, Z. 2005. Rao's quadratic entropy as a measure of functional diversity based on multiple traits. - J Veg Sci 16: 533-540.

Burgio, K. R., Davis, K. E., Dreiss, L. M., Klingbeil, B. T., Cisneros, L. M., Presley, S. J., Willig, M. R. 2019. Phylogenetic supertree and functional trait database for all extant parrots. - Data in Brief 24:103882.

Brito, D. and Oprea, M. 2009. Mismatch of research effort and threat in avian conservation biology. - Trop Conserv Sci 2: 353-362. 
Brum FT, Graham CH, Costa GC, Hedges SB, Penone C, Radeloff VC, Rondinini C, Loyola R, and Davidson A.D. 2017. Global priorities for conservation across multiple dimensions of mammalian diversity. - Proceedings of the National Academy of Sciences 114:76417646.

Butchart, S. H., Clarke, M., Smith, R. J., Sykes, R. E., Scharlemann, J. P., Harfoot, M., Buchanan, G. M., Angulo, A., Balmford, A. and Bertzky, B. 2015. Shortfalls and solutions for meeting national and global conservation area targets. - Conserv Letters 8: 329-337.

Cardillo, M., Mace, G. M., Jones, K. E., Bielby, J., Bininda-Emonds, O. R., Sechrest, W., Orme, C. D. L. and Purvis, A. 2005. Multiple causes of high extinction risk in large mammal species. - Science 309:1239-1241.

Cardinale, B. J. Duffy, E.; Gonzalez, A.; Hooper, D.U.; Perrings, C.; Venail, P.; Narwani, A.; Mace, G.M:; Tilman, D.; Wardle, D.A.; Kinzig, A.P.; Daily, G.C.; Loreau, M.; Grace, J.B.; Larigauderie, A.; Srivastava, D. and Naeem, S. 2012. Biodiversity loss and its impact on humanity. - Nature 486: $59-67$.

Ceballos, G., Ehrlich, P. R., Barnosky, A. D., García, A., Pringle, R. M. and Palmer, T. M. 2015. Accelerated modern human- induced species losses: Entering the sixth mass extinction. Sci Advances 1: e1400253.

Chan, K. M. A., Shaw, M. R., Cameron, D. R., Underwood, E.C. and Daily, G. C. 2006. Conservation planning for ecosystem services. - PLoS Biol 4: 2138.

Chao, A., Chiu, C. and Jost, L. 2014. Unifying Species Diversity, Phylogenetic Diversity, Functional Diversity, and Related Similarity and Differentiation Measures Through Hill Numbers. - Annual Review of Ecology, Evolution, and Systematics 45: 297-324.

Cimon-Morin, J., Darveau, M. and Poulin, M. 2013. Fostering synergies between ecosystem services and biodiversity in conservation planning: A review. - Biol Conserv 166: 144154.

Davies, R. G., Orme, C. D. L., Webster, A. J., Jones, K. E., Blackburn, T. M. and Gaston, K. J. 2007. Environmental predictors of global parrot (Aves: Psittaciformes) species richness and phylogenetic diversity. - Global Ecol Biogeogr 16: 220-233.

De Bello, F., Lavergne, S., Meynard, C. N., Lepš, J. and Thuiller, W. 2010. The partitioning of diversity: Showing Theseus a way out of the labyrinth. - J Veg Sci 21: 992-1000.

del Hoyo, J., Collar, N. J., Christie, D. A., Elliott, A. and Fishpool, L. D. C. 2014. HBW and BirdLife International Illustrated Checklist of the Birds of the World Vol. 1. - Lynx Edicions.

Devictor, V., Mouillot, D., Meynard, C., Jiguet, F., Thuiller, W. and Mouquet, N. 2010. Spatial mismatch and congruence between taxonomic, phylogenetic and functional diversity: The need for integrative conservation strategies in a changing world. - Ecol Lett 13: 10301040 . 
Díaz, S., Lavorel, S., de Bello, F., Quétier, F., Grigulis, K. and Robson, T. M. 2007. Incorporating plant functional diversity effects in ecosystem service assessments. - Proc Natl Acad Sci USA 104: 20684.

Ducatez S. and Lefebvre L. 2014. Patterns of Research Effort in Birds. PLoS One 9: e89955.

Faleiro, F. V., Machado, R. B. and Loyola, R. D. 2013. Defining spatial conservation priorities in the face of land-use and climate change. - Biol Conserv 158: 248-257.

Gilardi, J. D. and Toft, C. A. 2012. Parrots eat nutritious foods despite toxins. - PloS One, 7: e38293.

Isaac, N. J., Turvey, S. T., Collen, B., Waterman, C. and Baillie, J. E. 2007. Mammals on the EDGE: conservation priorities based on threat and phylogeny. - PloS One 2: e296.

IUCN. 2015. The IUCN Red List of Threatened Species. Version 2015. Retrieved from www.iucnredlist.org

Jetz, W., Thomas, G., Joy, J., Redding, D., Hartmann, K. and Mooers, A. 2014. Global Distribution and Conservation of Evolutionary Distinctness in Birds. - Current Biol 24: 919-930.

Jones, M. J., Fielding, A. and Sullivan, M. 2006. Analysing extinction risk in parrots using decision trees. - Biodivers Conserv 15: 1993-2007.

Jones, K. R., Watson, J. E. M., Possingham, H. P. and Klein, C. J. 2016. Incorporating climate change into spatial conservation prioritisation: A review. - Biol Conserv 194: 121-130.

Jost, L. 2006. Entropy and diversity. - Oikos 113: 363-375.

Kosman, E., K.R. Burgio, S.J. Presley, M.R. Willig, and S.M. Scheiner. 2019. Conservation prioritization based on trait-based metrics illustrated with global parrot distributions. Divers Distrib 25: 1156- 1165.

Li, Z. and Powell, C. M. 2001. An outline of the palaeogeographic evolution of the Australasian region since the beginning of the Neoproterozoic. - Earth-Sci Rev 53: 237-277.

Lopez, B., Burgio, K., Carlucci, M., Palmquist, K., Parada, A., Weinberger, V. and Hurlbert, A. 2016. A new framework for inferring community assembly processes using phylogenetic information, relevant traits and environmental gradients. - One Ecosystem 1: e9501.

Mace, G. M., Collar, N. J., Gaston, K. J., Hilton-Taylor, C., Akçakaya, H. R., Leader-Williams, N., Milner-Gulland, E. J. and Stuart, S. N. 2008. Quantification of extinction risk: IUCN's system for classifying threatened species. - Conserv Biol 22: 1424-1442.

Mace, G. M. 2004. The role of taxonomy in species conservation. - Philos Trans R Soc B Biol Sci 359: 711-719.

Mace, G. M., Gittleman, J. L. and Purvis, A. 2003. Preserving the tree of life. - Science 300: 1707.

Maechler, M., Rousseeuw, P., Struyf, A., Hubert, M. and Hornik, K. 2012. Cluster: cluster analysis basics and extensions. - R package version 1: 56. 
Marsden, S. J., Royle, K. and Downs, C. 2015. Abundance and abundance change in the world's parrots. - Ibis 157: 219-229.

Mazel, F., Guilhaumon, F., Mouquet, N., Devictor, V., Gravel, D., Renaud, J., Cianciaruso, M. V., Loyola, R., Diniz-Filho, J. A. F., Mouillot, D. and Thuiller, W. 2014. Multifaceted diversity-area relationships reveal global hotspots of mammalian species, trait and lineage diversity. - Global Ecol Biogeogr 23: 836-847.

Moilanen A, Wilson KA, Possingham H. 2009. Spatial conservation prioritization: Quantitative methods and computational tools. - Oxford University Press

Myers, N., Mittermeier, R. A., Mittermeier, C. G., Da Fonseca, G. A. and Kent, J. 2000. Biodiversity hotspots for conservation priorities. - Nature 403: 853-858.

Naeem, S., Duffy, J. E. and Zavaleta, E. 2012. The Functions of Biological Diversity in an Age of Extinction. - Science 336: 1401.

Naeem, S. and Li, S. 1997. Biodiversity enhances ecosystem reliability. - Nature 390: 507-509.

Olah, G., Butchart, S. H., Symes, A., Guzmán, I. M., Cunningham, R., Brightsmith, D. J. and Heinsohn, R. 2016. Ecological and socio-economic factors affecting extinction risk in parrots. - Biodivers Conserv 25: 205-223.

Paradis, E., Claude, J. and Strimmer, K. 2004. APE: Analyses of phylogenetics and evolution in $R$ language. - Bioinformatics 20: 289-290.

Pires, S. F. 2012. The illegal parrot trade: a literature review. - Global Crime 13: 176-190.

Pollock LJ, Thuiller W, and Jetz W. 2017. Large conservation gains possible for global biodiversity facets. - Nature 546:141.

Reid, W. V. 1998. Biodiversity hotspots. - Trends Ecol Evol 13: 275-280.

Renton, K., Salinas-Melgoza, A., De Labra-Hernández, M. Á. and de la Parra-Martínez, Sylvia Margarita 2015. Resource requirements of parrots: nest site selectivity and dietary plasticity of Psittaciformes. - J Ornithol 156: 73-90.

Renton, K. and Brightsmith, D. J. 2009. Cavity use and reproductive success of nesting macaws in lowland forest of southeast Peru; Uso de cavidades y éxito reproductivo de las guacamayas en la selva tropical húmeda del sureste de Perú. - J Field Ornithol 80: 1-8.

Safi, K., Cianciaruso, M. V., Loyola, R. D., Brito, D., Armour-Marshall, K. and Diniz-Filho, J. A. F. 2011. Understanding global patterns of mammalian functional and phylogenetic diversity. - Philos Trans R Soc B Biol Sci 366: 2536-2544.

Schmitz, O. J., Lawler, J. J., Beier, P., Groves, C., Knight, G., Boyce Jr, D. A., Bulluck, J., Johnston, K. M., Klein, M. L. and Muller, K. 2015. Conserving biodiversity: practical guidance about climate change adaptation approaches in support of land-use planning. Nat Areas J 35: 190-203.

Schweizer, M., Seehausen, O., Güntert, M. and Hertwig, S. T. 2010. The evolutionary diversification of parrots supports a taxon pulse model with multiple trans-oceanic dispersal events and local radiations. - Mol Phylogenet Evol 54: 984-994. 
442

443

444

445

446

Seddon, A. W., Macias-Fauria, M., Long, P. R., Benz, D. and Willis, K. J. 2016. Sensitivity of global terrestrial ecosystems to climate variability. - Nature 531: 229-232.

Snyder, N. F. R., McGowan, P., Gilardi, J. and Grajal, A. 2000. Parrots: status survey and conservation action plan 2000-2004. - IUCN.

Spasojevic, M. J. and Suding, K. N. 2012. Inferring community assembly mechanisms from functional diversity patterns: The importance of multiple assembly processes. - J Ecol 100: 652-661.

Srivastava, D. S., Cadotte, M. W., MacDonald, A. A. M., Marushia, R. G. and Mirotchnick, N. 2012. Phylogenetic diversity and the functioning of ecosystems. - Ecol Lett 15: 637-648.

Tella, J. L., Baños-Villalba, A., Hernández-Brito, D., Rojas, A., Pacífico, E., Díaz-Luque, J. A., Carrete, M., Blanco, G. and Hiraldo, F. 2015. Parrots as overlooked seed dispersers. Front Ecol Environ 13: 338-339.

Tingley, M. W., Darling, E. S. and Wilcove, D. S. 2014. Fine- and coarse- filter conservation strategies in a time of climate change. - Ann NY Acad Sci 13221: 92-109.

Turner, W. R., Bradley, B. A., Estes, L. D., Hole, D. G., Oppenheimer, M. and Wilcove, D. S. 2010. Climate change: helping nature survive the human response. - Conserv Letters 3: 304-312.

Uehling, J. J., Tallant, J. and Pruett-Jones, S. 2019. Status of naturalized parrots in the United States. J Ornith 160: 907-921.

Urban, M. C. 2015. Accelerating extinction risk from climate change. - Science 348: 571-573.

White, R. L., Strubbe, D., Dallimer, M., Davies, Z. G., Davis, A. J., Edelaar, P., Groombridge, J. J., Jackson, H., Menchetti, M., Mori, E. and Nikolov, B. P., 2019. Assessing the ecological and societal impacts of alien parrots in Europe using a transparent and inclusive evidence-mapping scheme. - NeoBiota 48: 45-69.

Wilson, K. A., Auerbach, N. A., Sam, K., Magini, A. G., Moss, A. S. L., Langhans, S. D., Budiharta, S., Terzano, D. and Meijaard, E. 2016. Conservation Research Is Not Happening Where It Is Most Needed. - PLoS Biol 14: e1002413.

Wright, T. F., Schirtzinger, E. E., Matsumoto, T., Eberhard, J. R., Graves, G. R., Sanchez, J. J., Capelli, S., Muller, H., Scharpegge, J., Chambers, G. K. and Fleischer, R. C. 2008. A multilocus molecular phylogeny of the parrots (Psittaciformes): support for a Gondwanan origin during the cretaceous. - Mol Biol Evol 25: 2141-2156. 
Tablo 1: Funotionel aftributes that toflect micho exes (firnotional anmpononta) woro ised th ostimato flunotionel biodivornity of permot. essomblages for oroh $.500 \mathrm{~km}^{2}$ grid ooll.

\begin{tabular}{|c|c|c|c|}
\hline Type of Dete & Funotional Component & Atributio & Treit Vehrog \\
\hline \multirow[t]{23}{*}{ Culezorivil } & Divol & Crarion & 1,0 \\
\hline & & Invertebrales & 1,0 \\
\hline & & Sneill & 1,0 \\
\hline & & Pollen & 1,0 \\
\hline & & Nectar & 1,0 \\
\hline & & Flower & 1,0 \\
\hline & & Seed & 1,0 \\
\hline & & Nut & 1,0 \\
\hline & & Fruit & 1,0 \\
\hline & & Plant matter & 1,0 \\
\hline & & Roots & 1,0 \\
\hline & & Frumpi & 1,0 \\
\hline & Foraging Strategy & Gben & 1,0 \\
\hline & & $\operatorname{Dig}$ & 1,0 \\
\hline & & Soryongo & 1,0 \\
\hline & & Gmas & 1,0 \\
\hline & & Flower probe & 1,0 \\
\hline & & Fxonvite & 1,0 \\
\hline & Foraging Loontion & Water & 1,0 \\
\hline & & Ground & 1,0 \\
\hline & & Veqpotion & 1,0 \\
\hline & & Subcemenpy & 1,0 \\
\hline & & Cermopy & 1,0 \\
\hline \multirow[t]{7}{*}{ Mensural } & Body Sizo & Mess & $\operatorname{Meen}(\mathrm{g})$ \\
\hline & & Lorifth & Mean (Mrr) \\
\hline & & Tunsus & $\operatorname{Mem}(\mathrm{mIL})$ \\
\hline & & Cullmen & Mean (min) \\
\hline & & Wing & Mean (min) \\
\hline & & 'l'ail & Meen (mm) \\
\hline & Kanpe Sizo & Area & $\mathrm{km}^{2}$ \\
\hline
\end{tabular}




\section{FIGURE LEGENDS}

Figure 1. Global map of parrot (a) species richness (S) and (b) functional diversity (FD; Rao's Q, based on Hill numbers). Functional traits in the analysis include: diet, foraging location, foraging strategy, body size and shape characteristics, and range size.

Figure 2. Global map of phylogenetic diversity (PD) of parrots (Rao's Q, based on Hill numbers) associated with a diagrammatic representation of the diversification of major clades and their biogeographic affinities. Images of Gondwanaland were redrawn from Li and Powell (2001), with paths of dispersal obtained from Schweizer et al. (2010). Subfamilial designations on the cladogram are: (a) Arinae, (b) Psittacinae, (c) Coracopseinae, (d) Agapornithinae, (e) Loriinae, (f) Platycercinae, and (g) Psittaculinae. All parrot images are from the Public Domain. Figure 3. Global map of the Integrated Biodiversity Index (IBI) for parrots, which is the sum of numbers equivalents of species richness, phylogenetic diversity, and functional diversity for each grid cell, with each of the three components scaled from 0 to 1.

Figure 4. Graphical comparison of (a) species richness (S), (b) phylogenetic (PD), and (c) functional (FD) diversity patterns as well as (d) IBI of South America and (e) the difference between species richness $(\mathrm{S})$ and IBI $(\Delta \mathrm{IBI})$, illustrating that correlation on a global level does not predict congruence of hotspots of each dimension at smaller spatial scales. To calculate $\Delta$ IBI, we scaled the results of panels (a) and (d) to 0-1 (to make them comparable) and subtracted $\mathrm{S}$ from IBI, resulting in $\Delta \mathrm{IBI}$, which can range from -1 to 1 . Positive scores (purple) are areas more emphasized by IBI, whereas negative scores (green) are areas more emphasized by species richness. Yellow scores indicate approximately equal emphasis. 


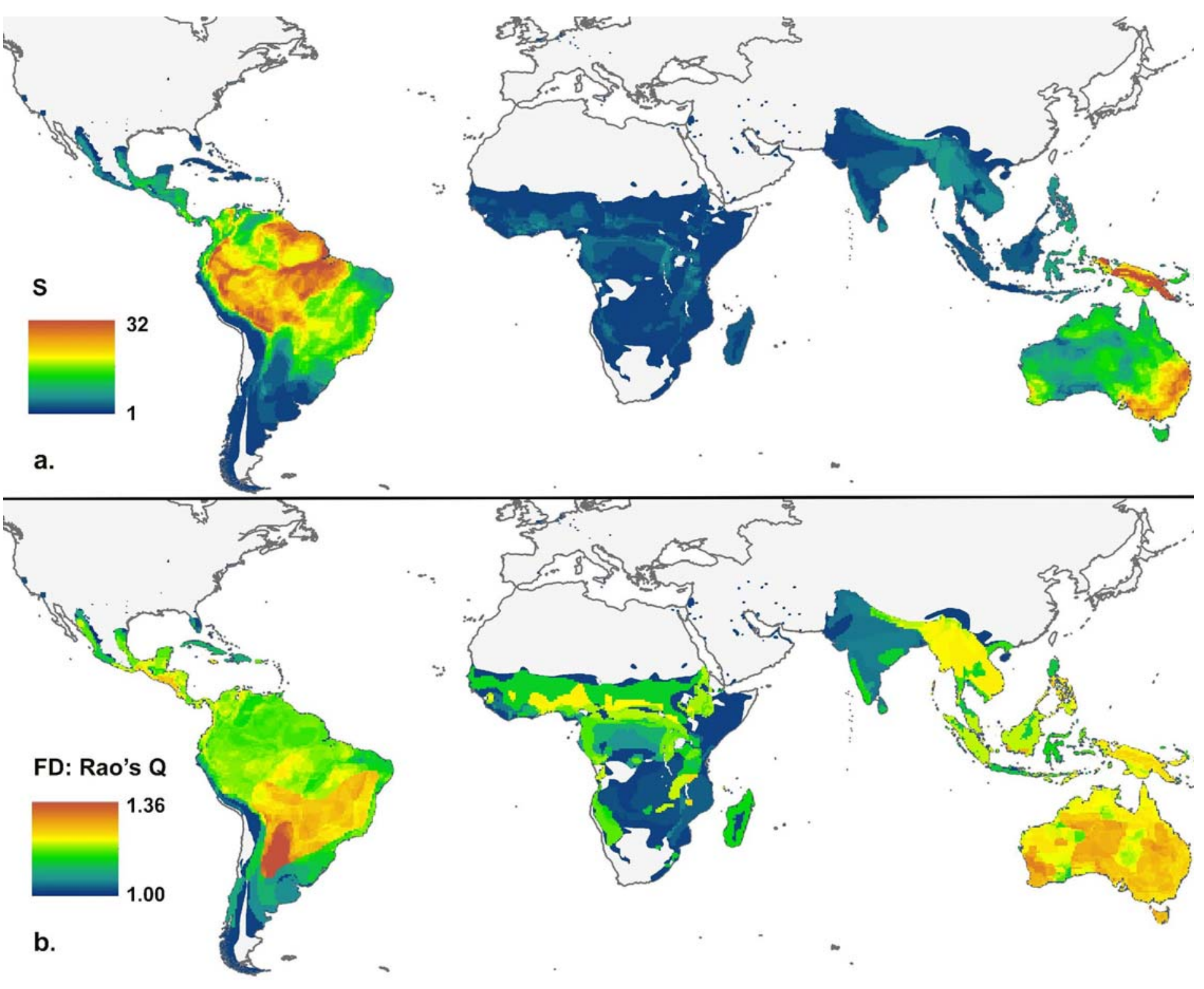

Figure 1 


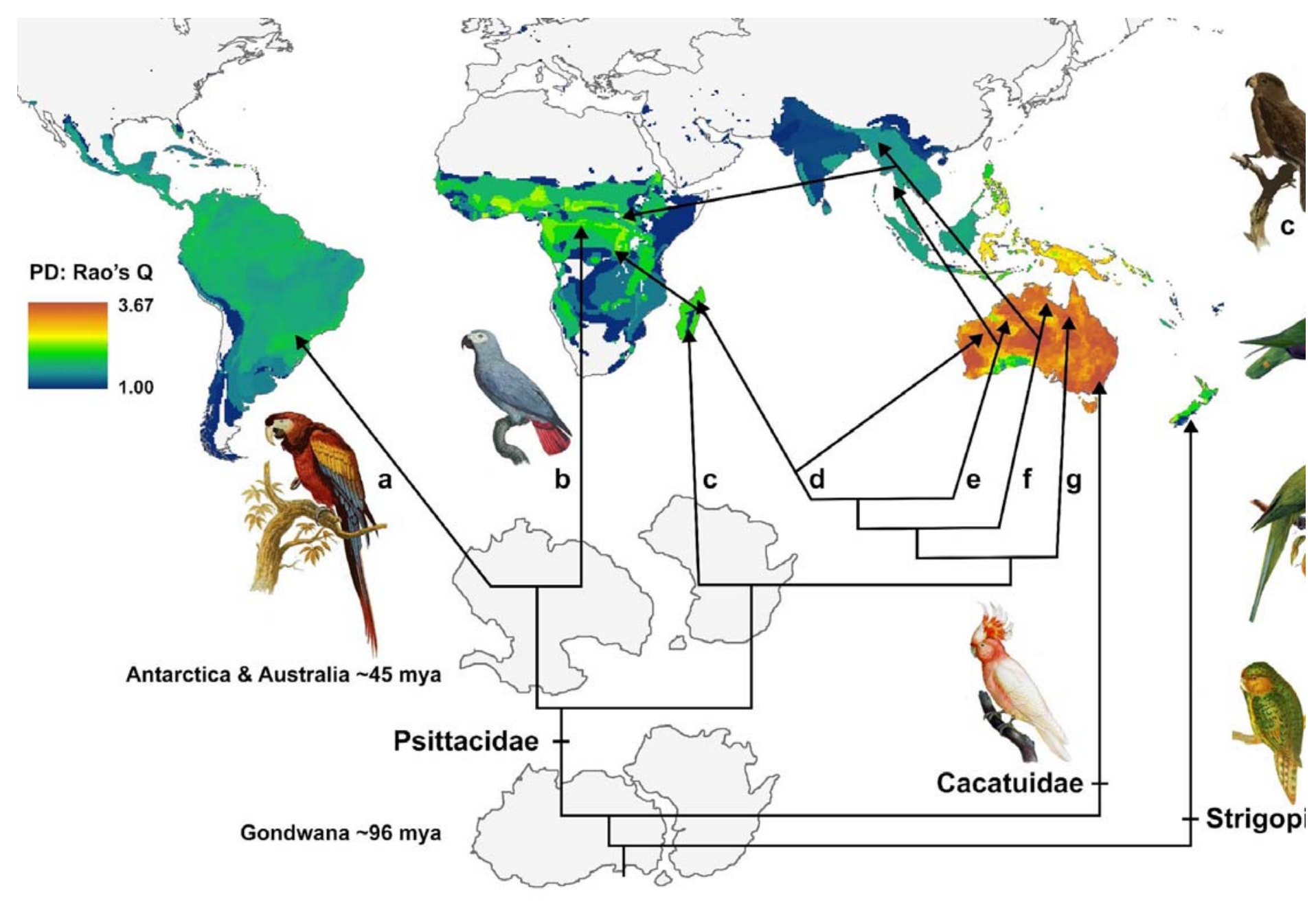

Figure 2 


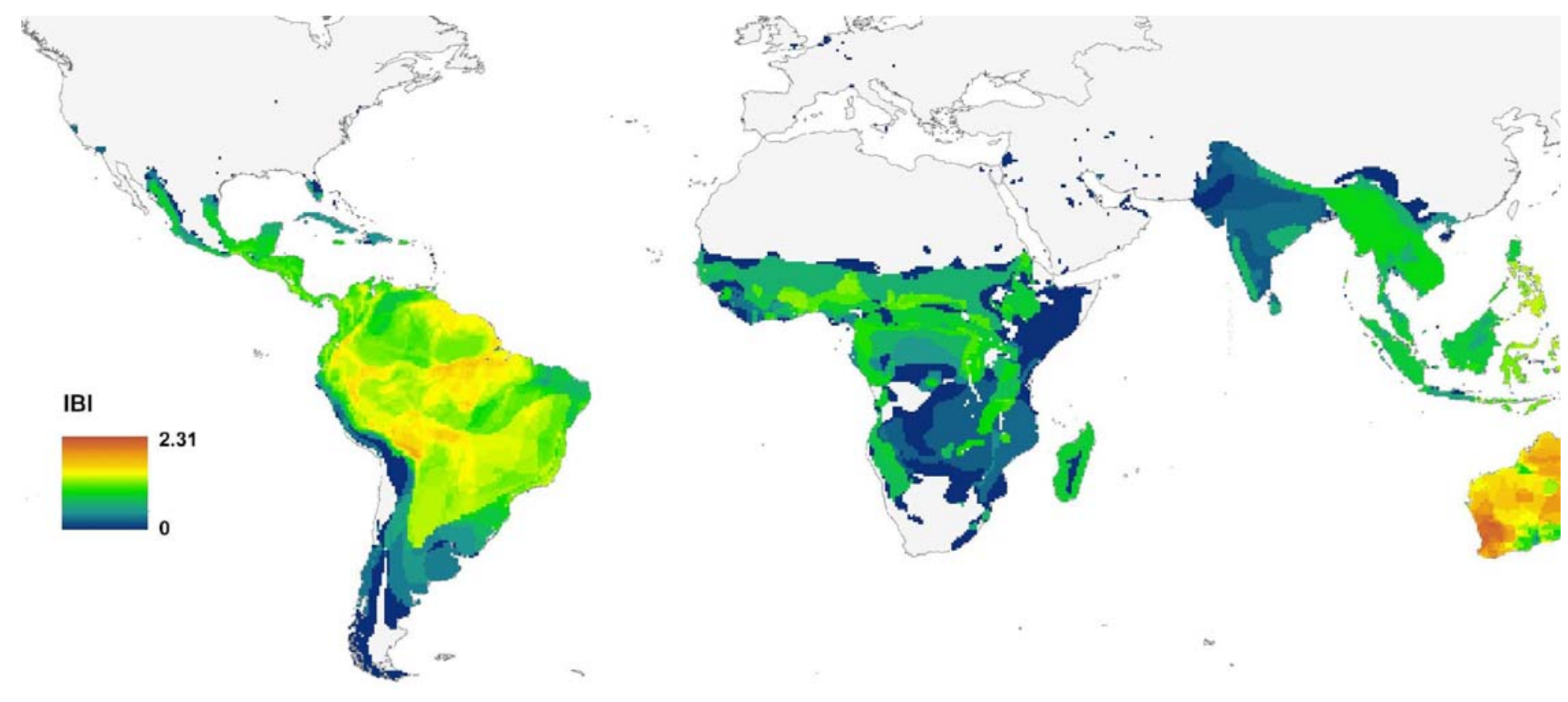

Figure 3 

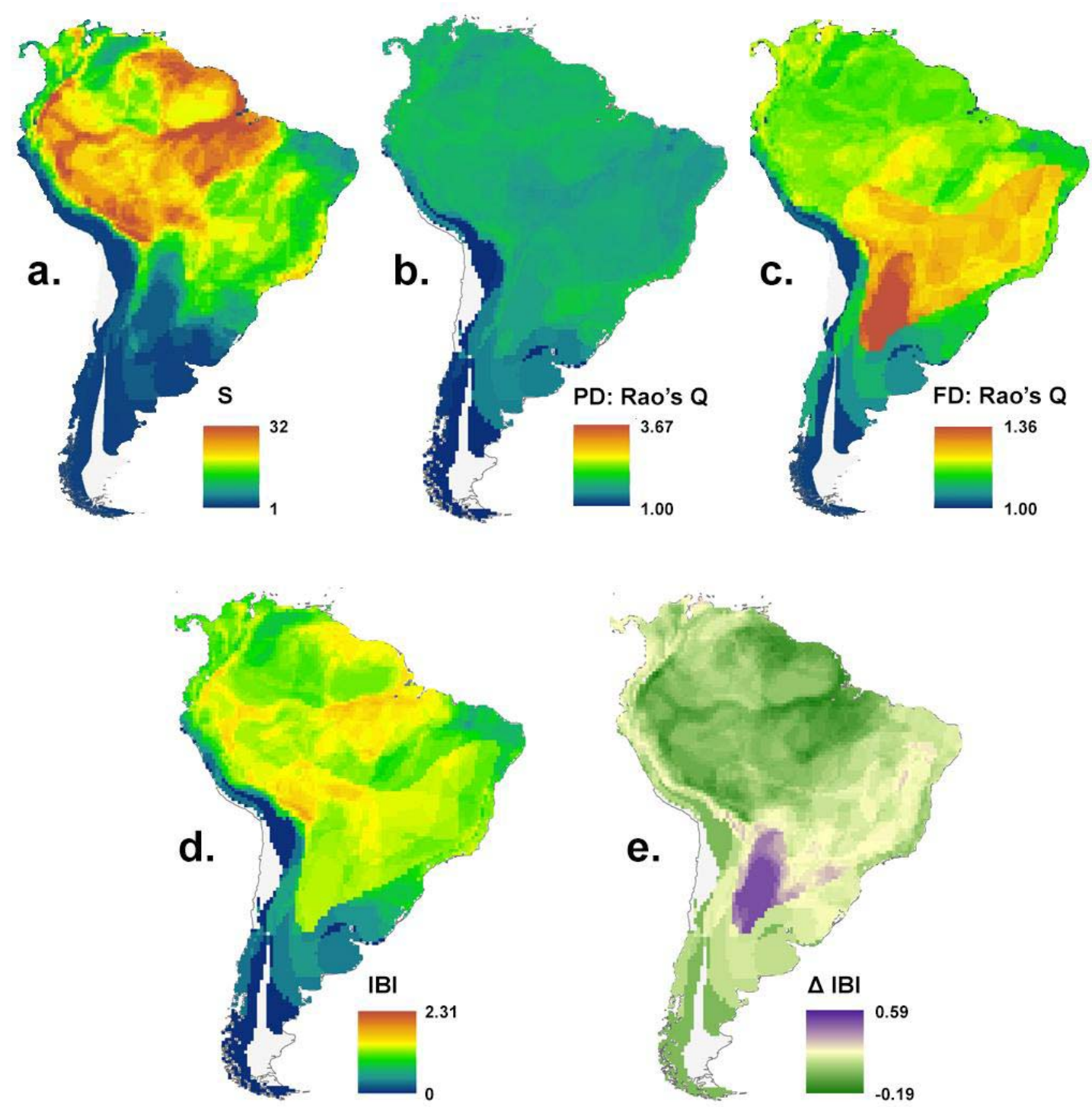

Figure 4 